\title{
Optimization of the design of a polymer flat plate solar collector
}

\author{
A.C. Mintsa Do Ango*, M. Medale, C. Abid \\ Aix-Marseille Université, CNRS, IUSTI UMR 7343, 13453 Marseille, France
}

\begin{abstract}
This work presents numerical simulations aimed at optimizing the design of polymer flat plate solar collectors. Solar collectors' absorbers are usually made of copper or aluminum and, although they offer good performance, they are consequently expensive. In com-parison, using polymer can improve solar collectors economic competitiveness. In this paper, we propose a numerical study of a new design for a solar collector to assess the influence of the design parameters (air gap thickness, collector's length) and of the operating conditions (mass flow rate, incident solar radiation, inlet temperature) on efficiency. This work outlines the main trends concerning the leading parameters impacting the polymer flat plate solar collector's efficiency.
\end{abstract}

Keywords: Solar energy; Solar collector; CFD simulation; Thermal analysis; Parametric study

\section{Introduction}

Solar energy is free and clean, but must be first captured and converted, using solar collectors or PV-panels. Solar collectors absorb the incident solar radiation, convert it into heat and transfer this heat to a coolant (water, air, oil, etc.) flowing through the collector. There are two types of solar collectors: non-concentrating and concentrating (Kalogirou, 2004; Mekhilef et al., 2011). Flat plate solar collectors (FPSCs) belong to the first category, and consist of an absorber (usually made of copper or aluminum) and a glazing, separated by an air layer. The absorber's bottom and sides are insulated. A coolant flows through the network of pipes below the absorber to evacuate the collected energy. As they provide thermal energy at low or medium temperature, FPSCs are thus generally used for water heating, and they have many applications such as service hot water production, space heating and cooling, solar

\footnotetext{
* Corresponding author. Tel.: +33 0650833860 .

E-mail address: mintsa.andrecharles@gmail.com (A.C. Mintsa Do Ango).
}

refrigeration, industrial process heat and solar desalination. But the materials they are fabricated from make them expensive. Many studies have been performed to understand the thermal behavior of FPSCs whose efficiency depends on both the value of the incident solar radiation on the absorber and it's thermal losses (Benkhelifa, 1998; Filloux, 2001; Cardonnel, 1983; Hossain et al., 2011; Kundu, 2010; Kumar and Mullick, xxxx; Vestlund et al., 2012; Kumar and Rosen, 2010; Jaisankar et al., 2011; Sookdeo and Siddiqui, 2010; Kuo et al., 2011; Dagdougui et al., 2011; Alvarez et al., 2010; Zambolin and Del, 2010; Akthar and Mullick, 2012). Benkhelifa (1998) shows that the glazed side of the collector is the source of the most important thermal losses - between $10 \%$ and $35 \%$ of them, according to others studies (Hossain et al., 2011; Filloux, 2001; Cardonnel, 1983). They indicate that the physical mechanisms at work involve three transfer modes (optical, radiative and convective) roughly in the same proportions (1/3 for each of them).

Many authors proposed works on the studying of performance and optimization of classic FPSC (made of copper or aluminum), but there is not much publications 
on the thermal behavior and performance estimations of polymer FPSC (Martinopoulos et al., 2010; Cristofari et al., 2002). Martinopoulos (Martinopoulos et al., 2010) made an experimental and numerical work on a novel honeycomb polycarbonate collector in which the solar energy is directly absorbed by the black colored coolant. He determined experimentally the efficiency of the collector, which is similar to low-cost FPSC commercially available, he numerically modeled the flow field development and the temperature distribution, the model was validated with experimental data. A numerical work on a copolymer FPSC has been made by Cristofari et al. (2002), in which the influence of the insulation thickness, the flow rate and the coolant layer thickness have all been analyzed. The results show that there are two parameters which are influenced the most namely, the coolant mass flow rate and the fluid layer thickness. The conclusion of this work was to use a copolymer for the design of a FPSC hence reducing the weight by more than half the classic FPSC and giving similar performances.

Many studies have been performed and techniques have been developed to reduce FPSC thermal losses. All these techniques can be divided into two categories. The first one regroups those that resort to modifying the properties and form of the glazing, and the second one those focusing on the modification of the absorber shape. In the first, Hollands (1965), Hollands (1973), like Arnold et al. (1977), Arnold et al. (1976), suggested placing a honeycomb between the glazing and the absorber to reduce radiation losses in the latter. This alternative is interesting, but its implementation for industrial production is problematic. In his work, Amraqui [Amraqui, 2009] therefore replaced the honeycomb with multiple vertical partitions separated from the absorber to avoid conduction heat transfer. These partitions reduce the flow of natural convection between the glazing and absorber. Slaman and Griessen (2009) replaced the glazing by a polycarbonate prismatic structure to reduce solar overheating - but thereby limiting solar absorption and performance. In the same theme, Hellstrom and Adsten (2003) investigated the impact of the materials' optical properties on the FPSC's performance by using a Teflon film, a Teflon honeycomb, an antireflection treatment of the glazing or combinations of these improvements. A Teflon film used as second glazing improves the performance, and installing a Teflon honeycomb doubles that gain, while the best solution consists in combining a Teflon honeycomb with an antireflection-treated glazing. In the second category, Varol and Oztop (2008) made a numerical analysis who showed that flow and thermal fields are affected by the shape of the absorber, with a more important heat transfer occurring with a wavy absorber than with a flat one. Fan et al. (2007) made theoretical and experimental investigations on the flow and the temperature distribution in an FPSC with an absorber consisting of horizontally inclined strips. He found that the FPSC's efficiency decreases if the mass fl- ow rate is too small, and the risk of coolant boiling is increased by a high temperature inlet and a too large tilt angle. All of these studies gave us an overview of FPSC's thermal behavior and have provided many techniques to reduce their thermal losses. But these works have only focused on specific points of the FPSCs (air gap, glazing, absorber shape, etc.) and are generally realized with a classic solar collector. Moreover an economic approach has rarely been mentioned.

Other studies have been performed on photovoltaic/ thermal hybrid solar collectors. Flat plate PV/T look very similar to classic FPSC from global point of view, but difference is the PV panel is attached on the top of absorber (Charalambous et al., 2007; Ibrahim et al., 2011). Many authors performed numerical and experimental studies dealing with the evaluation of the influence of various parameters, such as length collector, mass flow rate, cover number, absorber plate design and temperature inlet on the collector efficiency (Charalambous et al., 2007). However the thermal energy to be extracted to the coolant in PV/T hybrid solar collectors are much less than that in purely thermal FPSC. Indeed the working principle of hybrid $\mathrm{PV} / \mathrm{T}$ is to reduce the $\mathrm{PV}$ cells temperature in order to maintain a good electrical efficiency. Therefore in this type of collector the coolant is always at very low temperature compare to classic FPSC. And the thermal phenomenas occurring in theses collectors don't have the same intensity of the classic FPSC.

The challenge to our study is optimize FPSCs and improve their economic competitiveness by using both an absorber and a glazing made of polymer. This work was part of SolaireDuo R\&D program for which we proposed to perform a parametric study on the FPSC's length, air gap thickness, coolant mass flow rate, incoming solar radiation and inlet temperature in order to assess their effects on this type of FPSC. The aim of this work is to highlight the trends, allowing the designer to find a way to optimize this polymer FPSC prototype and thus increase their competitiveness.

\section{Polymer FPSC modeling}

Fig. 1 represents a module which is the component of the flat plate solar collector prototype studied. This module is $2 \mathrm{~m}$ long, $20 \mathrm{~cm}$ wide and $6.2 \mathrm{~cm}$ thick. A module is formed by a distributor, absorber, manifold, glazing shape, insulation and air layer between the absorber and the glazing. This module consists of a polycarbonate absorber (painted black) topped by a transparent polycarbonate glazing. The whole is insulated with glass wool. The thickness of the air gap between the glazing and the absorber is given by the parameter $e$. The coolant (water) flows through the absorber channels with mass flow rates $\dot{m}$. The inlet water is located at the bottom and the outlet, at the top. $L$ is the solar collector length and $I$ is the incident solar flux on the absorber. The solar collector is tilted by $45^{\circ}$ (see Fig. 2). 


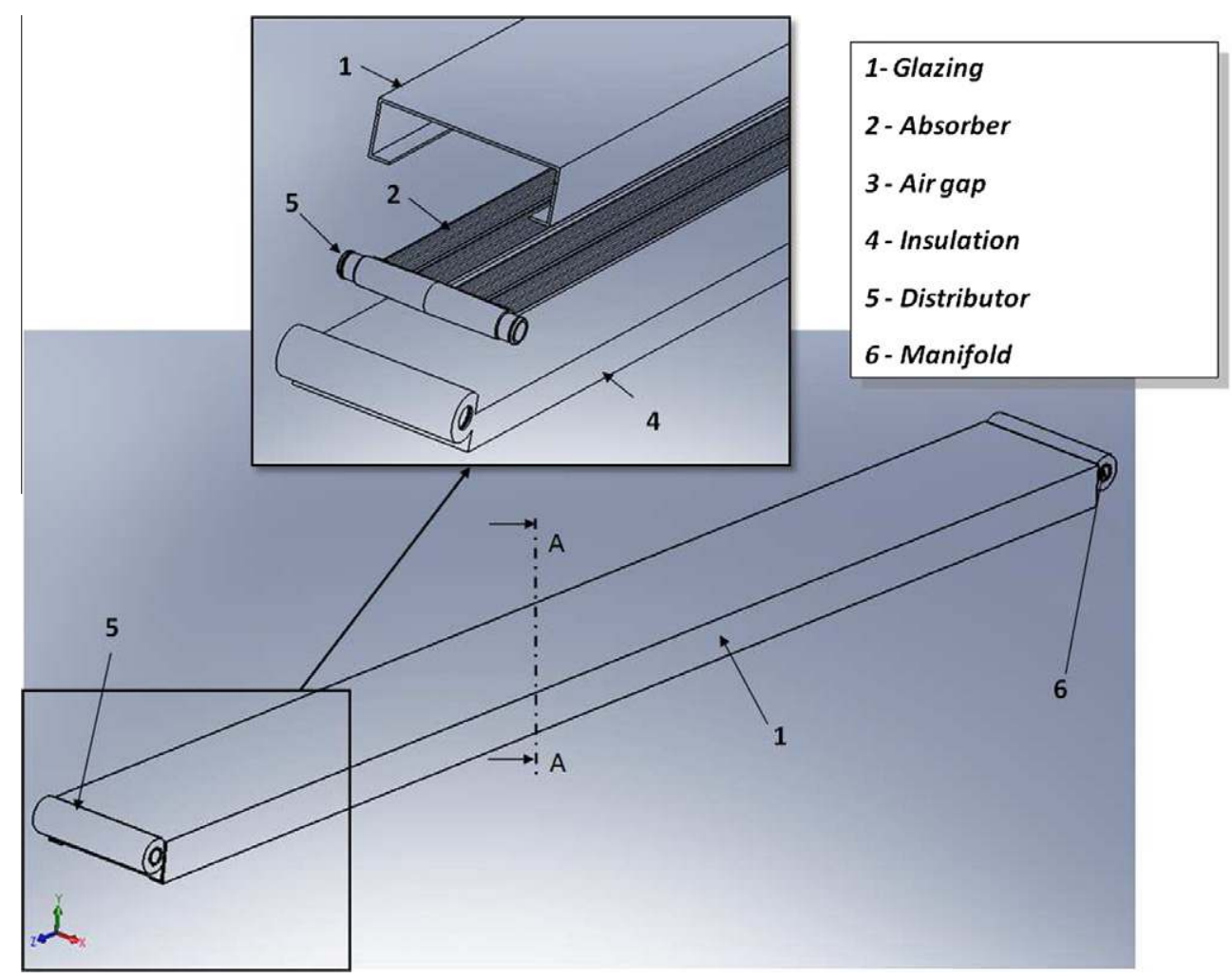

Fig. 1. The module of the prototype of the polymer flat plate solar collector.

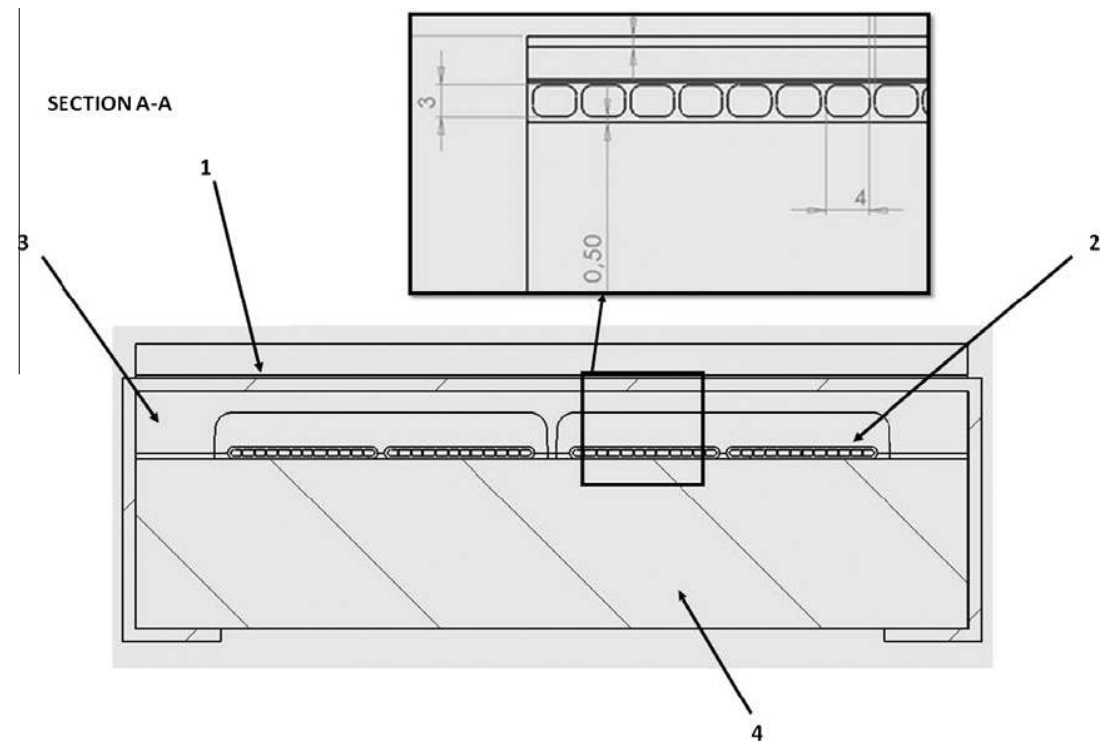

Fig. 2. The A-A section of the polymer flat plate solar collector.

All of this work is conducted with commercial software CFD Star-CCM+. In this work just a portion of the polymer PFSC is simulated, the dimensions of this portion are $1 \mathrm{~m} \times 90.5 \mathrm{~mm}$ (Fig. 3). The section is taken from the central part of the prototype FPSC to avoid edge effects. The distributor and the manifold are not taken into account. (see Fig. 4).

\subsection{Physical assumptions}

- The physical properties of the solids (the glazing, the absorber and the insulation) are constant.

- All the solid surfaces are gray and diffuse. 


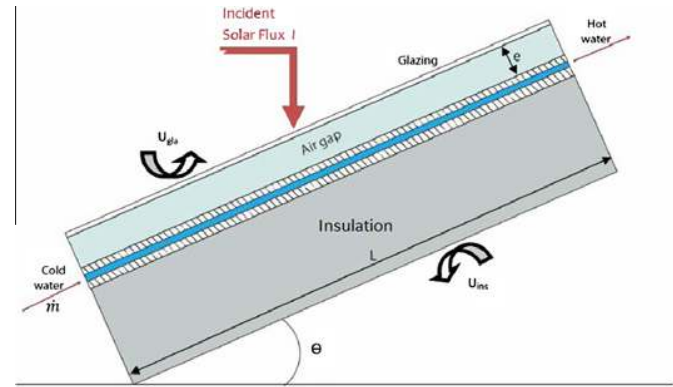

(a)

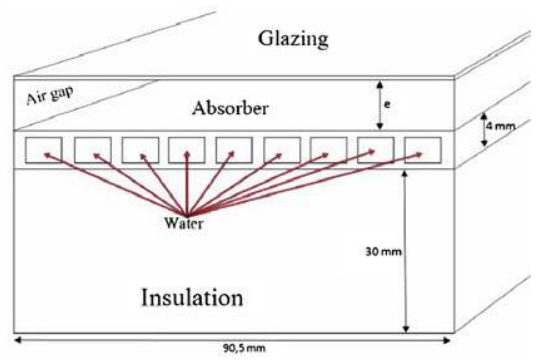

(b)

Fig. 3. (a) Longitudinal section of a prototype polymer FPSC, (b) transversal section of a prototype polymer FPSC.

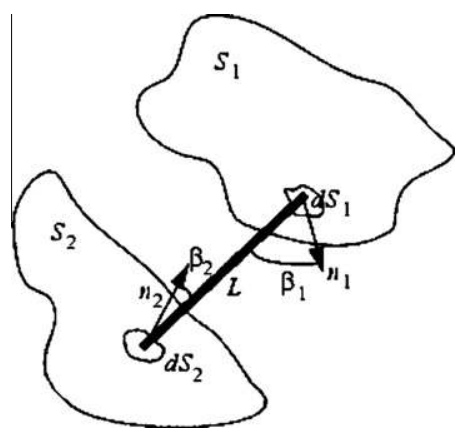

Fig. 4. Surface to surface radiation exchange.

The coolant is considered an incompressible newtonian fluid.

- The coolant flow through the channels is laminar (since at the highest mass flow rate the Reynolds number is 60 , thus the flow in the channels is laminar).

- The effects of buoyancy are not taken in account in the coolant flow (because of the thermal sedimentation in the channels the buoyancy effects are negligible (Sookdeo and Siddiqui, 2010))

- The air is an ideal transparent gas.

- The system is considered stationary.

\subsection{Governing equations}

The governing equations are:

Mass conversion

$\operatorname{div}(\overrightarrow{\rho v})=0$

Momentum balance equation

$$
\begin{aligned}
\nabla \cdot(\rho \vec{v} \otimes \vec{v})= & -\nabla P+\nabla \cdot\left[v\left(\nabla v+\nabla^{T} v\right)-\frac{2}{3} \cdot \nabla \cdot \vec{v} I\right] \\
& +\vec{F}_{v}
\end{aligned}
$$

and the energy balance equation,

$$
\operatorname{div}[(\rho H+P) \vec{v}]=\overline{\bar{\tau}}: \nabla \vec{v}-\nabla \cdot \vec{\phi}
$$

where $v$ is the cinematic viscosity $\left(\mathrm{m}^{2} \mathrm{~s}^{-1}\right), \rho$ is the density $\left(\mathrm{kg} \mathrm{m}^{-3}\right), \vec{v}$ is the velocity vector $\left(\mathrm{m} \mathrm{s}^{-1}\right), P$ is the pressure (Pa), $\tau$ is the viscous stress tensor $(\mathrm{Pa})$ and $H$ is the mass energy density $(\mathbf{J})$.

The air is considered an ideal gas, so the state equation is:

$P=\rho . R . T$

where $R$ is the perfect gas constant $\left(\mathrm{J} \mathrm{K}^{-1} \mathrm{~kg}^{-1}\right)$.

In the solid, the heat transfer is governed by the conduction mode:

$\vec{\phi}=-\lambda \cdot \operatorname{grad} T$

with $\phi$ the heat flux ( $\mathrm{W} \mathrm{m}^{-2}$ ) and $\lambda$ the thermal conductivity $\left(\mathrm{W} \mathrm{m}^{-1} \mathrm{~K}^{-1}\right)$.

To simulate the radiative effects, a Surface to Surface (S2S) thermal Radiation model is used which is based on the enclosure theory for gray diffuse surfaces (Cd-Adapco, 2009). All surfaces in the model are isotropic, diffuse and radiant. Thus the amount of radiation exchanged between the surfaces depends only on the radiation intensity, the location, the relative orientation of the surfaces and their geometry. The total irradiation on a surface $i$ is given by the following equations:

$\Phi_{i}=S_{i} \cdot G_{i}=\sum_{j=1}^{N_{p}} F_{j-i} \cdot \tau_{i j} . J_{j} \cdot S_{j}$

$F_{i-j}=\frac{1}{S_{i}} \cdot \int_{S_{i}} \frac{\cos \left(\beta_{i}\right) \cdot \cos \left(\beta_{j}\right)}{\pi \cdot L^{2}} d S_{i} d S_{j}$

$J_{i}=r_{i} \cdot G_{i}+E_{i}$

$E_{i}=\epsilon_{i} \cdot \Delta \sigma \cdot T_{i}^{4}$

with $\Phi_{i}$ is the total incident radiation on the $i$ surface $\left(\mathrm{W} \mathrm{m}^{-2}\right), I$ is the incoming solar radiation on the $S_{i}$ surface ( $\mathrm{W} \mathrm{m}^{-2}$ ), $F_{j-i}$ is the geometric view factor between the $i$ surface and another $j$ surface. $G_{i}$ is the incident flux on the $i$ surface $\left(\mathrm{W} \mathrm{m}^{-2}\right), r_{i}$ is the $i$ surface reflectivity. $J_{i}$ is the radiosity, which represents total energy departing from the $i$ surface $\left(\mathrm{W} \mathrm{m}^{-2}\right) . E_{i}$ represents the energy emitted by the $i$ surface $\left(\mathrm{W} \mathrm{m}^{-2}\right) . L$ is the distance between the two surfaces $(\mathrm{m}) \cdot \tau_{i-j}$ represents cumulated effects of all the transmissive surfaces between the $i$ surface and the $j$ surface. 
In the polymer FPSC the global thermal balance is given by the following equation:

$I=Q_{u}+Q_{l}$

$\eta=\frac{Q_{u}}{I}$

where $I$ is the incident radiation on the absorber $(\mathrm{W}), Q_{u}$ is the output power $(\mathrm{W})$, and $Q_{l}$ is the thermal losses (W). The FPSC's efficiency is defined by the ratio between the amount of energy given to coolant $Q_{u}$ and the incoming solar radiation on the absorber. The efficiency is calculated in Eq. (11).

The power output $Q_{u}$ is defined by the global enthalpic balance:

$Q_{u}=n \cdot \dot{m} \cdot C_{p} \cdot\left(T_{\text {out }}-T_{\text {in }}\right)$

where $\dot{m}$ is the coolant mass flow rate $\left(\mathrm{kg} \mathrm{s}^{-1}\right), C_{p}$ is the heat capacity at constant pressure $\left(\mathrm{J} \mathrm{kg}^{-1} \mathrm{~K}^{-1}\right), n$ is the number of channels, and $T_{\text {out }}$ and $T_{\text {in }}$ are the outlet and inlet coolant bulk temperatures (C).

\subsection{Boundary conditions}

In the present study, the two limiting vertical planes are considered as symmetry planes. On the upper surface of the glazing and the external backside of the insulation, a global heat loss coefficient is applied to simulate the heat exchange with the environment $U_{\text {gla }}$ and $U_{i n s},\left(\mathrm{~W} \mathrm{~m}^{-2} \mathrm{~K}^{-1}\right)$. A condition of mass flow inlet $(\dot{m})$ is imposed at the entrance of the coolant channels and at the exit a flow split outlet conditions is imposed. On upper surface of the absorber,
Table 4

Values used in the parametric study of the mass flow rate $(\dot{m})$.

\begin{tabular}{lllll}
\hline$\dot{m}\left(\mathrm{~kg} \mathrm{~s}^{-1}\right)$ & $L(\mathrm{~m})$ & $e(\mathrm{~m})$ & $I\left(\mathrm{~W} \mathrm{~m}^{-2}\right)$ & $T_{\text {in }}(\mathrm{C})$ \\
\hline $2.5 e^{-5}$ & 1 & $10^{-2}$ & 800 & 20 \\
$5 e^{-5}$ & 1 & $10^{-2}$ & 800 & 20 \\
$1 e^{-4}$ & 1 & $10^{-2}$ & 800 & 20 \\
\hline
\end{tabular}

the heat flux $(I)$ is imposed. (Tables 1-3).

\section{Parametric study}

The parametric studies of the design parameters and operating conditions of the polymer FPSC are performed to understand its thermal behavior. The different parameters values are based on the two french leaders (Giordano and Clipsol) of Solar collector manufacturing informations. The influences of the FPSC's length $L$, air gap thickness $e$, coolant mass flow rate $\dot{m}$, incoming solar radiation on the absorber $I$ and inlet temperature $T_{i n}$ are evaluated. For a series of simulations the evaluated parameter varies in the range of set values while the others parameters are kept fixed. The following tables give the different values fixed for the studied parameters. (see Tables 5 and 6).

\section{Results and discussion}

\subsection{Influence of the collector's length}

Table 5

Values used in the parametric study of the incident radiation flux $(I)$.

\begin{tabular}{lllll}
\hline$I\left(\mathrm{~W} \mathrm{~m}^{-2}\right)$ & $L(\mathrm{~m})$ & $e(\mathrm{~m})$ & $\dot{m}\left(\mathrm{~kg} \mathrm{~s}^{-1}\right)$ & $T_{\text {in }}(\mathrm{C})$ \\
\hline 350 & 0.5 & $10^{-2}$ & $2.5 e^{-5}$ & 20 \\
400 & 0.5 & $10^{-2}$ & $2.5 e^{-5}$ & 20 \\
500 & 0.5 & $10^{-2}$ & $2.5 e^{-5}$ & 20 \\
600 & 0.5 & $10^{-2}$ & $2.5 e^{-5}$ & 20 \\
800 & 0.5 & $10^{-2}$ & $2.5 e^{-5}$ & 20 \\
1200 & 0.5 & $10^{-2}$ & $2.5 e^{-5}$ & 20 \\
\hline
\end{tabular}

Table 2

Values used in the parametric study of the collector's length $(L)$.

\begin{tabular}{lllll}
\hline$L(\mathrm{~m})$ & $e(\mathrm{~m})$ & $\dot{m}\left(\mathrm{~kg} \mathrm{~s}^{-1}\right)$ & $I\left(\mathrm{~W} \mathrm{~m}^{-2}\right)$ & $T_{\text {in }}(\mathrm{C})$ \\
\hline 0,5 & $10^{-2}$ & $2.5 e^{-5}$ & 800 & 20 \\
1 & $10^{-2}$ & $5 e^{-5}$ & 800 & 20 \\
2 & $10^{-2}$ & $1 e^{-4}$ & 800 & 20 \\
\hline
\end{tabular}

Table 3

Values used in the parametric study of the air gap thickness $(e)$.

\begin{tabular}{lllll}
\hline$e(\mathrm{~m})$ & $L(\mathrm{~m})$ & $\dot{m}\left(\mathrm{~kg} \mathrm{~s}^{-1}\right)$ & $I\left(\mathrm{~W} \mathrm{~m}^{-2}\right)$ & $T_{\text {in }}(\mathrm{C})$ \\
\hline $3 e^{-3}$ & 1 & $5 e^{-5}$ & 800 & 20 \\
$7 e^{-3}$ & 1 & $5 e^{-5}$ & 800 & 20 \\
$10^{-2}$ & 1 & $5 e^{-5}$ & 800 & 20 \\
$11 e^{-3}$ & 1 & $5 e^{-5}$ & 800 & 20 \\
$13 e^{-3}$ & 1 & $5 e^{-5}$ & 800 & 20 \\
\hline
\end{tabular}

Table 6

Values used in the parametric study of the inlet coolant temperature $\left(T_{i n}\right)$.

\begin{tabular}{lllll}
\hline$T_{\text {in }}(\mathrm{C})$ & $I\left(\mathrm{~W} \mathrm{~m}^{-2}\right)$ & $L(\mathrm{~m})$ & $e(\mathrm{~m})$ & $\dot{m}\left(\mathrm{~kg} \mathrm{~s}^{-1}\right)$ \\
\hline 20 & 800 & 0.5 & $10^{-2}$ & $2.5 e^{-5}$ \\
30 & 800 & 0.5 & $10^{-2}$ & $2.5 e^{-5}$ \\
40 & 800 & 0.5 & $10^{-2}$ & $2.5 e^{-5}$ \\
\hline
\end{tabular}

Table 7

Values for the influence of length on the operating mass flowrate.

\begin{tabular}{llll}
\hline$L(\mathrm{~m})$ & $l(\mathrm{~m})$ & $S\left(\mathrm{~m}^{2}\right)$ & $\dot{m}\left(1 \mathrm{~h}^{-1}\right)$ \\
\hline 0.5 & 0.090 & 0.045 & 20 \\
1 & 0.090 & 0.09 & 40 \\
2 & 0.090 & 0.18 & 80 \\
\hline
\end{tabular}



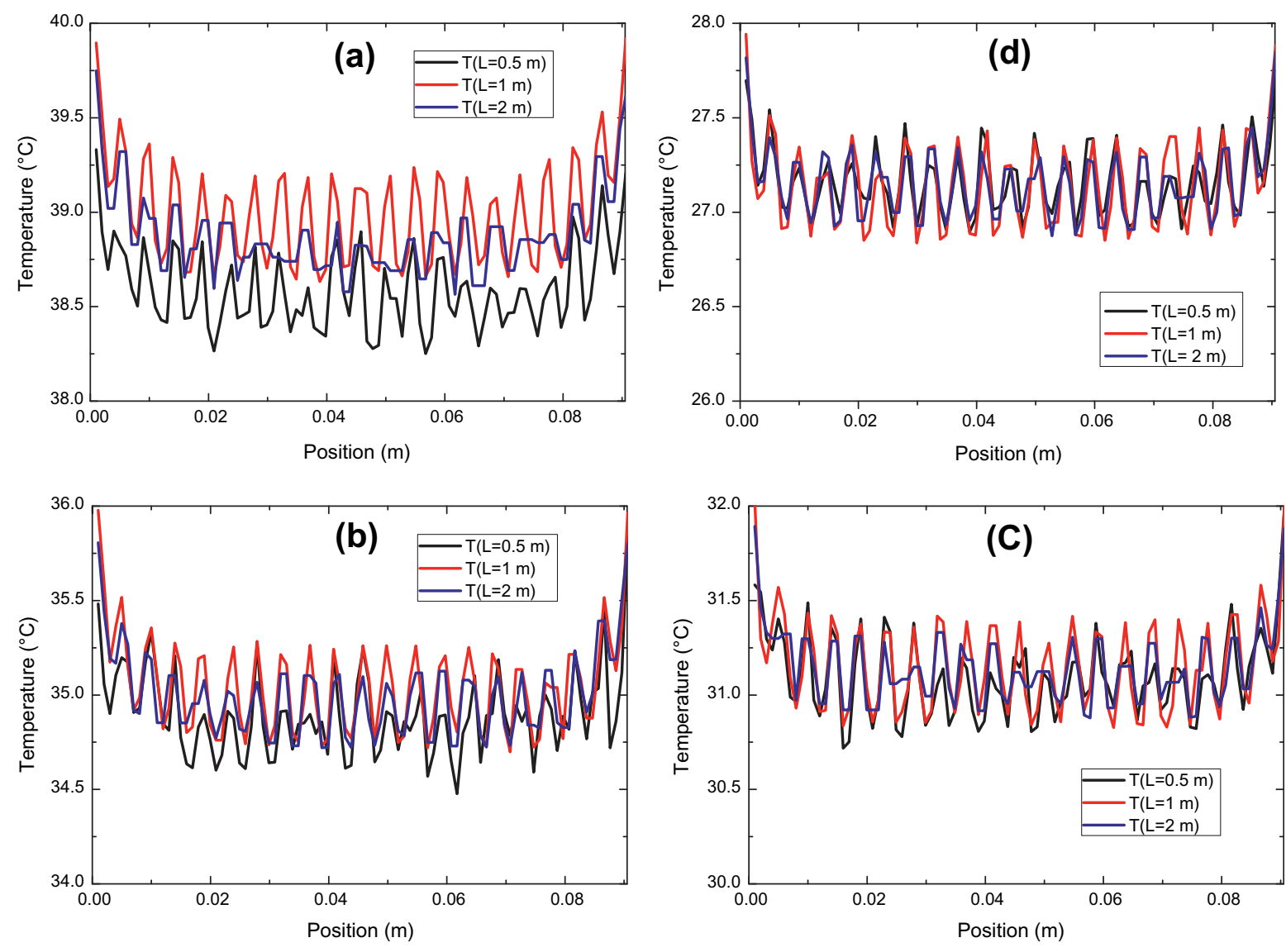

Fig. 5. Temperature profiles at the absorber's upper surface, (a) for $Z=1$, (b) for $Z=3 / 4$, (c) for $Z=1 / 2$ and (d) for $Z=1 / 4$.

In this section, the effects of the polymer FPSC's Length $L$ on the thermal behavior are computed with the parameter values according to Table 7 . Because of the conditions imposed by operating standards, only $L$ and $\dot{m}$ change. In fact, the mass flow rate $\dot{m}$ depends on the FPSC's surface ( $\dot{m}$ is given in $1 \mathrm{~h}^{-1} \mathrm{~m}^{-2}$ ).

Figs. 5 and 6 present the transversal temperature profiles on the upper surface of the absorber and the glazing's backside. These profiles are plotted at various $Z$ values which is the dimensionless length defined by $Z=L^{*} / L$ where $L^{*}$ is the length the plotted part of the curve and $L$ is the length of the polymer FPSC $(L / 4, L / 2,3 L / 4$ and $L$ ). The curves practically coincide for each position, which reflects the fact that the same mechanism occurs approximately at the same intensity. Table 8 shows that there is no significant difference for $\Delta T$ (difference between temperature inlet and temperature outlet) - for all length values, $\Delta T$ varies around $16.2^{\circ}$. According to Table 8 , the output heat flux $\left(\phi_{u}\right)$ values are really close $(747.3,747.8$ and $748.7 \mathrm{~W} \mathrm{~m}^{-2}$ respectively for $\mathrm{L}=0.5,1$ and $2 \mathrm{~m}$ ). This demonstrates that the collector's length does not have an influence on the polymer FPSC's efficiency. This result is due to the linear dependence between $L$ and $\dot{m}$ : when $L$ doubles, the incoming solar flux doubles too, thus the absorber receives twice as much energy. Moreover, the heat transfer between the absorber and the coolant depends on the convective heat transfer coefficient $h_{\text {conv }}$, and the value of the latter decreases along the downstream direction towards the establishment length to reach a constant value. This length is defined by the following equation:

$$
\begin{aligned}
& L_{e}^{T}=R e_{D} \cdot P_{r} \cdot D_{h}=\frac{\dot{m} \cdot D_{h}^{2} \cdot P_{r}}{\rho \cdot S_{c} \cdot v} \\
& R e_{D}=\frac{v \cdot D_{h}}{v}
\end{aligned}
$$

where $D_{h}=\frac{4 . S_{c}}{P_{w}}$ with $R e_{D}$, the Reynolds number, it represents the ratio of the inertia to viscous forces. $P_{r}$ is the Prandlt number, it represents the ratio of the momentum and thermal diffusivity. $S_{c}$ the channel section $\left(m^{2}\right)$ and $P_{w}$ is the wet perimeter.

According to Eq. (14) the thermal entrance length is a linear function of the mass flow rate. In this parametric study the mass flow rate is related to the FPSC's surface, therefore changing the length has no influence on the physical mechanism occurring in the FPSC. Consequently the polymer FPSC's length does not influence its performance. 

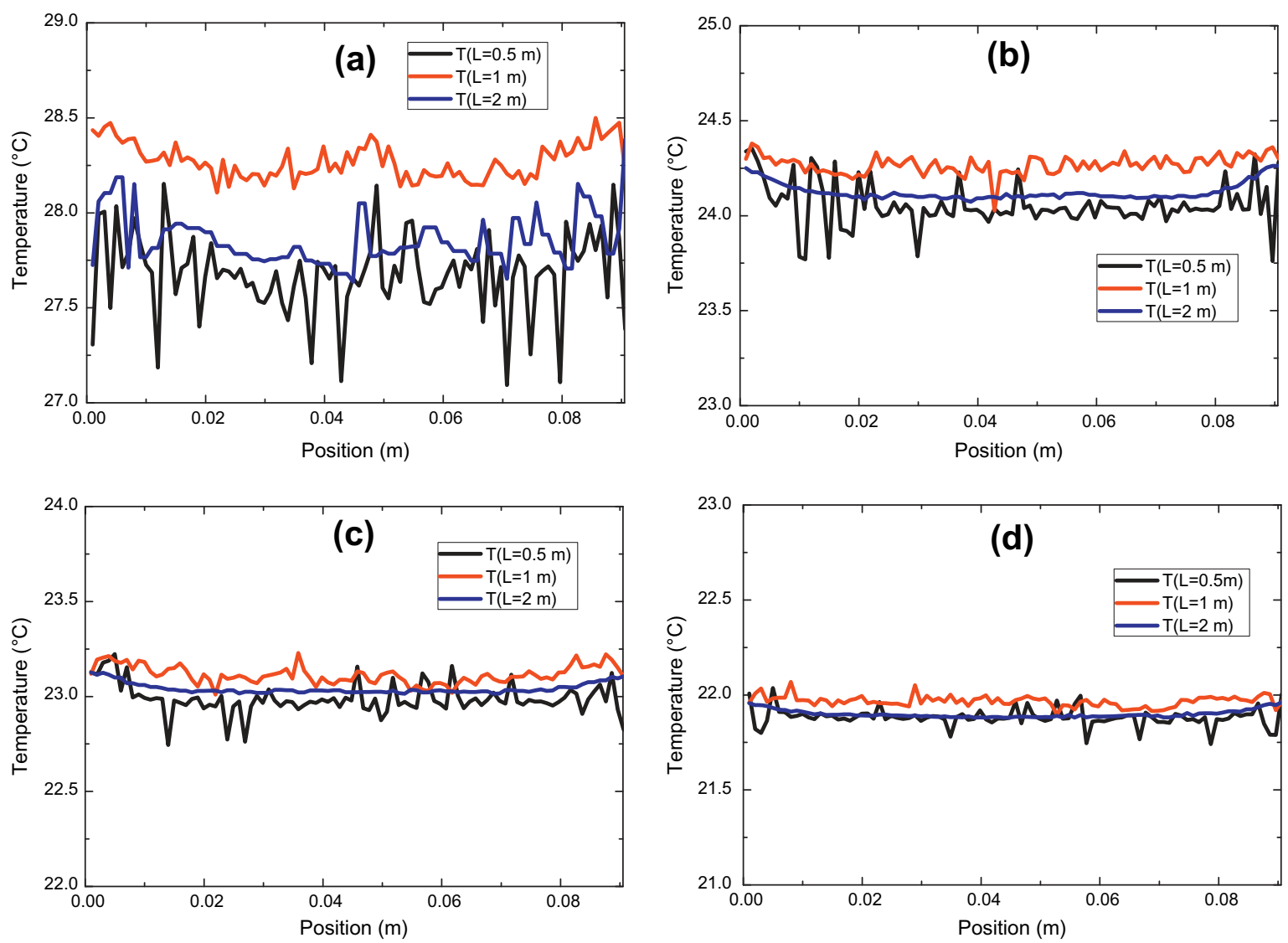

Fig. 6. Temperature profiles at the glazing's inner surface, (a) for $Z=1$, (b) for $Z=3 / 4$, (c) for $Z=1 / 2$ and (d) for $Z=1 / 4$.

Table 8

Results of the parametric study of the length.

\begin{tabular}{llll}
\hline$L(\mathrm{~m})$ & 0.5 & 1 & 2 \\
\hline$\dot{m}\left(\mathrm{~kg} \mathrm{~s}^{-1}\right)$ & $2.5 e^{-5}$ & $5 e^{-5}$ & $1 e^{-4}$ \\
$T_{\text {out }}(\mathrm{C})$ & 36.2 & 36.2 & 36.2 \\
$\Delta T(\mathrm{C})$ & 16.2 & 16.2 & 16.2 \\
$Q_{u}(\mathrm{~W})$ & 33.8 & 67.7 & 135.5 \\
$\phi_{u}\left(\mathrm{~W} \mathrm{~m}^{-2}\right)$ & 747.3 & 747.8 & 748.7 \\
$\eta(\%)$ & 93.4 & 93.5 & 93.6 \\
\hline
\end{tabular}

Table 9

Results of the parametric study of air gap thickness.

\begin{tabular}{llllll}
\hline$e(\mathrm{~mm})$ & 3 & 7 & 10 & 11 & 13 \\
\hline$T_{\text {out }}(\mathrm{C})$ & 35.7 & 35.8 & 36.2 & 36 & 36 \\
$\Delta T(\mathrm{C})$ & 15.7 & 15.8 & 16.2 & 16 & 16 \\
$T_{\text {glass }}(\mathrm{C})$ & 25 & 23 & 22.3 & 22.2 & 21.9 \\
$T_{\text {abs }}(\mathrm{C})$ & 30.8 & 31.1 & 31.3 & 31.2 & 30.7 \\
$Q_{u}(\mathrm{~W})$ & 65.8 & 66.1 & 67.7 & 67 & 66.9 \\
$\left.\phi_{u}(\mathrm{~W} \mathrm{~m})^{-2}\right)$ & 727 & 730.2 & 747.8 & 740.4 & 739.5 \\
$Q_{l}(\mathrm{~W})$ & 4.4 & 2.8 & 2.2 & 2 & 1.8 \\
$\left.\phi_{l}(\mathrm{~W} \mathrm{~m})^{-2}\right)$ & 48.7 & 30.6 & 23.9 & 21.9 & 19.8 \\
$\eta(\%)$ & 90.9 & 91.3 & 93.5 & 92.5 & 92.4 \\
\hline
\end{tabular}

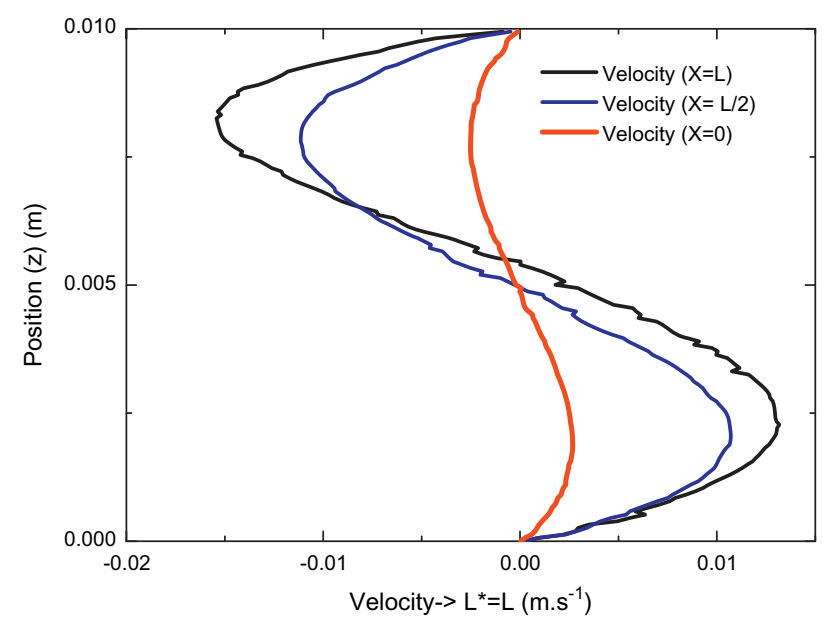

Fig. 7. Velocity profile in the air gap.

\subsection{Influence of the air gap thickness}

The following parametric study aims to highlight the influence of the air gap located between the glazing and the absorber on the polymer FPSC's efficiency. For the various $e$ values used, the results are summarized in Table 9 .

Fig. 7 shows velocity profiles located at different positions in the air gap. These profiles highlight the free convec- 


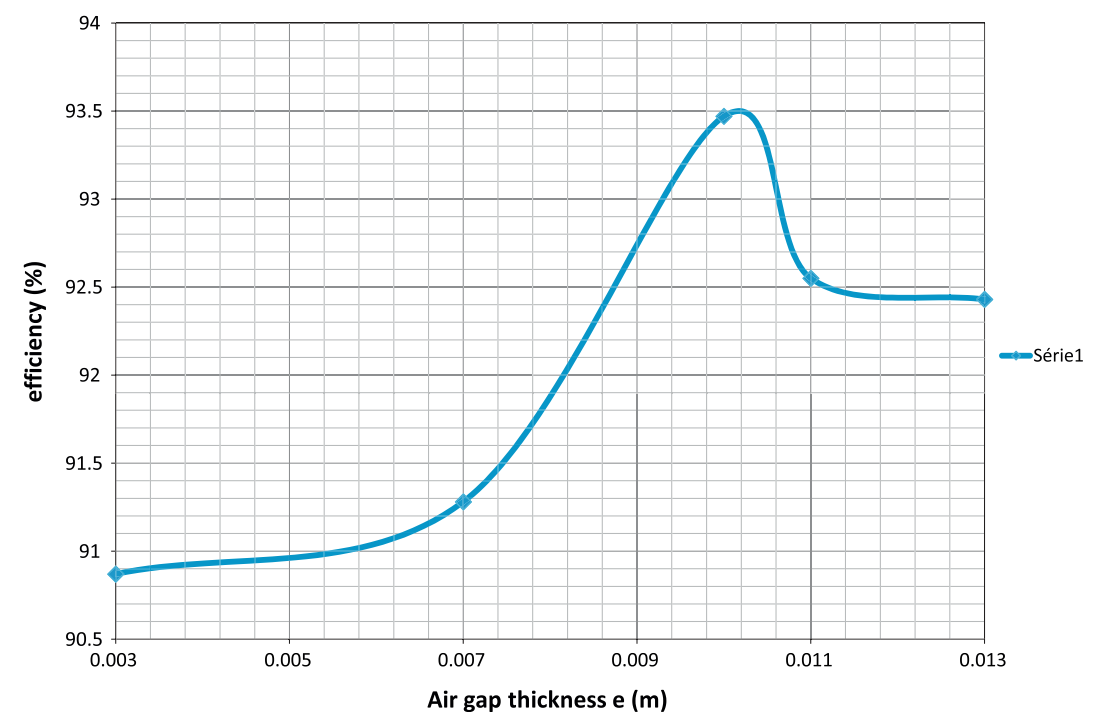

Fig. 8. Influence of air gap thickness.

tion occurring in the collector. The curves shape shows the presence of two areas of interest. At the bottom area air velocity increases along the absorber whereas in top it decreases along the glazing. There is a large air circulation between the absorber and the glazing. This convection motion results due to the presence of buoyancy forces within the air. Buoyancy is due to the presence of a fluid density gradient (with the ideal gas law, density depends on the temperature) and gravity. In bottom air velocity increases along the absorber whereas at the top it decreases along the glazing. There is a large air circulation between the absorber and glazing. This convection motion results of the presence of buoyancy forces within the fluid. Buoy- ancy is due to the presence of a fluid density gradient (with the ideal gas law the density depends on the temperature) and gravity. Efficiency increases for $e$ values less than $10 \mathrm{~mm}$ and decreases slowlPy for values of $e$ greater than $10 \mathrm{~mm}$. This variation is due to the heat transfer mode's contributions (convection and conduction). For the smaller values of air gap thickness $(e<10 \mathrm{~mm})$, conduction is predominant.

In Fig. 8, it can be observed that the curve has a maximum $(93.5 \%$ for $e=10 \mathrm{~mm})$. Efficiency increases for $e$ values less than $10 \mathrm{~mm}$ and decreases slowly for values of $e$ greater than $10 \mathrm{~mm}$. This variation is due to the heat transfer mode's contributions (convection and conduction). For

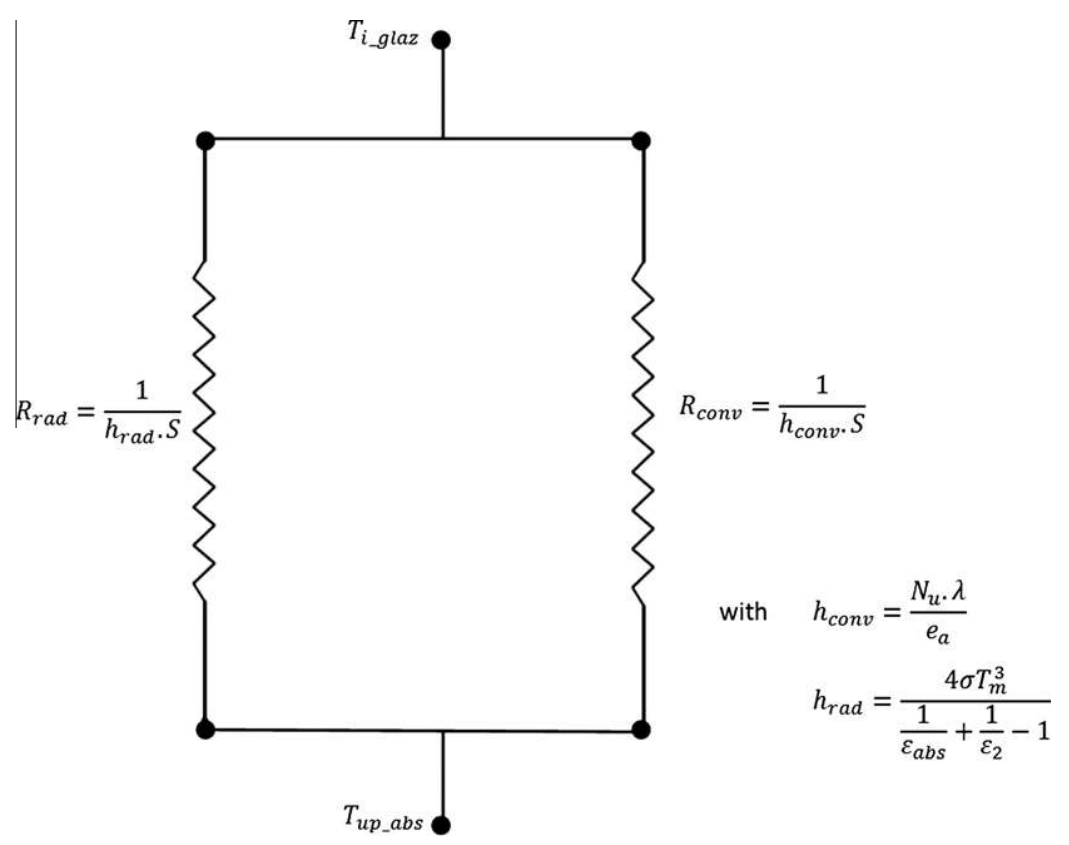

Fig. 9. Schematic network representation of the heat exchange between the absorber's upper surface and the glazing's inner surface. 
the smaller values of the air gap thickness $(e<10 \mathrm{~mm})$, conduction is dominant.

$\phi_{\text {cond }}=\frac{k \cdot \Delta T}{e}$

The heat transfer by conduction is defined by Eq. (15). By increasing the $e$ value, the insulating effect of the air gap thickness is improved. Observing the glazing heat losses clearly shows this: they decrease significantly when the thickness increases. For $e$ values greater than $10 \mathrm{~mm}$, the polymer FPSC's efficiency decreases while the glazing losses are still low. This decrease is due to natural convection increasing in the air gap.

Fig. 9 represents the schematic network of the heat exchange occurring in the air gap. We observe that the radiative thermal resistance $R_{\text {rad }}$ is independent of the air gap thickness $e$ and of the Nusselt number. The Nusselt number represents the ratio of the convective heat transfer over the conductive heat transfer. Then an important $N u$ indicates that the convective exchange is more important than the conductive exchange in the air gap.

$N u=S \cdot R a^{n} \cdot P r^{m}$

with $\frac{1}{4}<n<\frac{1}{3}$ and $0.012<m<0.074$.

$R_{a}=\frac{g \cdot \cos \theta \cdot \beta}{v \cdot \alpha} \cdot\left(T_{a b s}-T_{g l a}\right) \cdot e^{3}$

According to Eqs. (16) and (17), when $e$ increases the Nusselt Number $\mathrm{Nu}$ increases too, consequently the convective heat transfer dominates the conductive heat transfer. This explains the results obtained for $e>10 \mathrm{~mm}$. The temperature gradient between the absorber and the glazing creates an air flow, this flow takes energy from the absorber and looses it to the glazing. Increasing the air gap thickness thus causes greater heat losses in the absorber, and thus the coolant evacuates less energy than in the other cases. As it can see the efficiency depends on the air gap thickness, it exists an optimal value of this thickness, the same trends have been show by numerical study made by Ferahta et al. (2011).

\subsection{Influence of the mass flow rate}

The analysis presented in this section consists in an eval-

Table 10

Results of the parametric study of the mass flow rate.

\begin{tabular}{llll}
\hline$\dot{m}\left(\mathrm{~kg} \mathrm{~s}^{-1}\right)$ & $2.5 e^{-5}$ & $5 e^{-5}$ & $1 e^{-4}$ \\
\hline$T_{\text {out }}(\mathrm{C})$ & 51 & 36.2 & 28.3 \\
$\Delta T(\mathrm{C})$ & 31 & 16.2 & 8.3 \\
$T_{\text {glass-bottom }}(\mathrm{C})$ & 24.1 & 22.3 & 21.4 \\
$T_{\text {abs-top }}(\mathrm{C})$ & 39 & 31.3 & 27.1 \\
$Q_{u}(\mathrm{~W})$ & 64.7 & 67.7 & 69.1 \\
$\left.\phi_{u}(\mathrm{~W} \mathrm{~m})^{-2}\right)$ & 715.4 & 747.8 & 763.9 \\
$Q_{l}(\mathrm{~W})$ & 3.7 & 1.2 & 0.6 \\
$\left.\phi_{l}(\mathrm{~W} \mathrm{~m})^{-2}\right)$ & 40.4 & 13.4 & 6.4 \\
$\eta(\%)$ & 89.4 & 93.5 & 95.5 \\
\hline
\end{tabular}

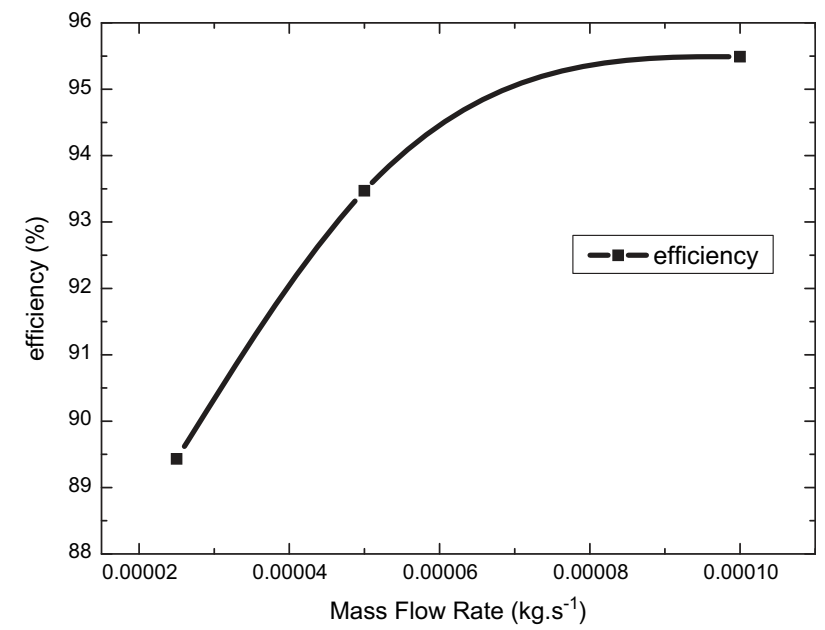

Fig. 10. Influence of mass flow rate $\dot{m}$.

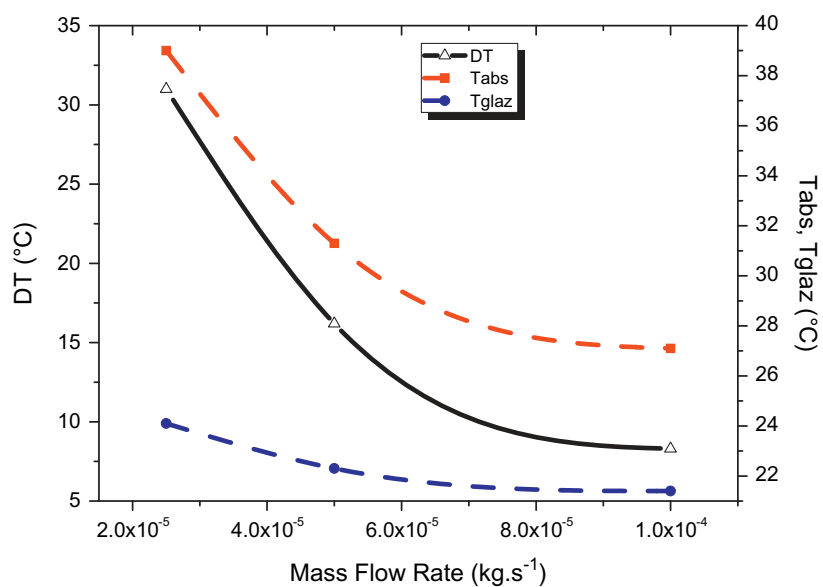

Fig. 11. Temperature evolution $\left(\Delta T, T_{a b s}\right.$ and $\left.T_{\text {glaz }}\right)$ in the study of the influence of the mass flow rate $\dot{m}$.

uation of the influence of the coolant's mass flow rate on the polymer FPSC's performances. The configurations of the simulations are summed up in Table 4.

Table 10 shows that the mass flow rate $\dot{m}$ has a non-linear influence on the performance of the polymer FPSC. The nominal mass flow rate $\left(\dot{m}=5.10^{-5} \mathrm{~kg} \mathrm{~s}^{-1}\right)$ is taken as the reference: halving it, $\Delta T$ increases by $15^{\circ} C$ or by doubling it $\Delta T$ is lowered by $8^{\circ} \mathrm{C}$. According to Fig. 10, the mass flow rate value giving the best efficiency is the highest one. By increasing the mass flow rate though, the efficiency tends to an asymptotic value. These trends are similar to the experimental work of Cristofari et al. (2002) where he has evaluated the mass flow rate influence on the flat plate solar collector. He concluded that the energy gained with a higher flow rate and using a low flow increases outlet temperature These results are explained by the entrance length, the bigger the entrance length, the more important the mass flow rate, hence more energy is 
Table 11

Results of the parametric study of the incident radiation flux.

\begin{tabular}{lllllll}
\hline$I\left(\mathrm{~W} \mathrm{~m}^{-2}\right)$ & 350 & 400 & 500 & 600 & 800 & 1200 \\
\hline$T_{\text {out }}(\mathrm{C})$ & 26.0 & 27.9 & 29.9 & 31.9 & 36 & 44 \\
$\Delta T(\mathrm{C})$ & 6.90 & 7.9 & 9.9 & 11.9 & 16 & 24 \\
$T_{\text {glass-inner }}(\mathrm{C})$ & 20.9 & 21.1 & 21.4 & 21.7 & 22.3 & 23.6 \\
$T_{\text {abs-upper }}(\mathrm{C})$ & 24.8 & 25.5 & 26.9 & 28.3 & 31.2 & 36.8 \\
$Q_{u}(\mathrm{~W})$ & 14.4 & 16.5 & 20.7 & 24.9 & 33.3 & 50.1 \\
$\left.\phi_{u}(\mathrm{~W} \mathrm{~m})^{-2}\right)$ & 318.7 & 365.3 & 458.2 & 551 & 736.7 & 1107.6 \\
$Q_{l}(\mathrm{~W})$ & 0.5 & 0.5 & 0.7 & 0.8 & 1.1 & 1.6 \\
$\left.\phi_{l}(\mathrm{~W} \mathrm{~m})^{-2}\right)$ & 5.1 & 5.8 & 7.3 & 8.8 & 11.8 & 17.9 \\
$\eta(\%)$ & 91.1 & 91.3 & 91.6 & 91.8 & 92.1 & 92.3 \\
\hline
\end{tabular}

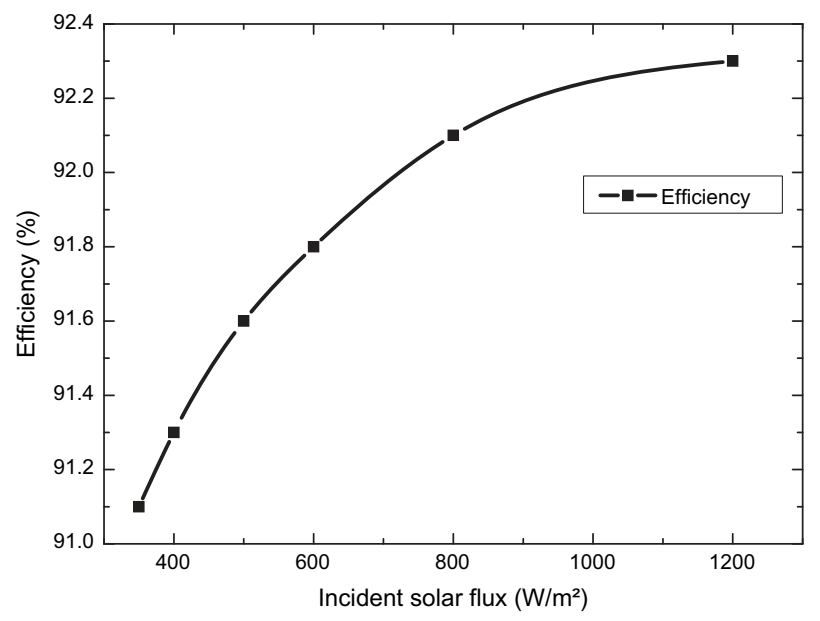

Fig. 12. Influence of incoming solar radiation $I$.

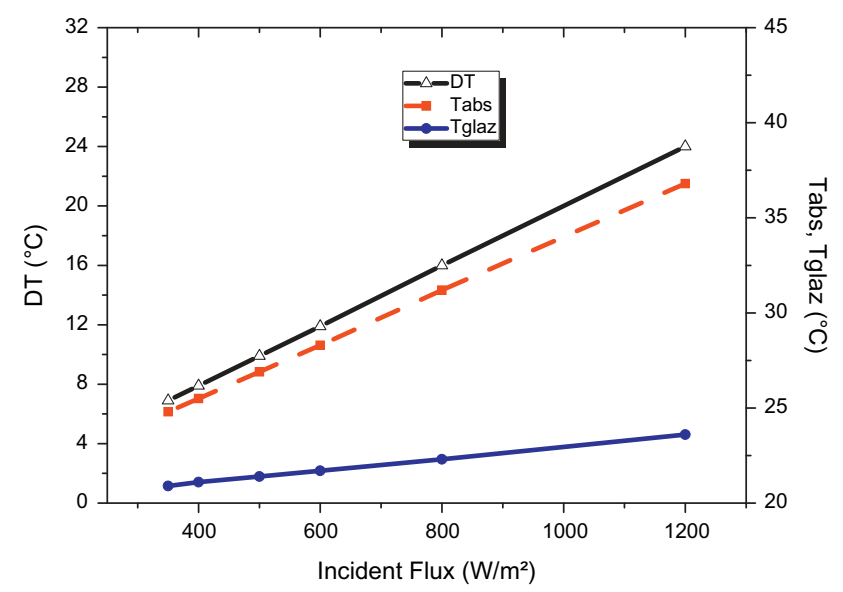

Fig. 13. Temperature evolution $\left(\Delta T, T_{a b s}\right.$ and $\left.T_{\text {glaz }}\right)$ in the study of incident heat flux influence $I$.

evacuated. On the other side, the coolant receives only a small temperature increase. (see Fig. 11).

\subsection{Influence of incident solar radiation}

In this part, the influence of incident solar radiation (denoted by $I$ ) on the polymer FPSC is calculated. $I$ is the heat flux imposed on the absorber, it represents the

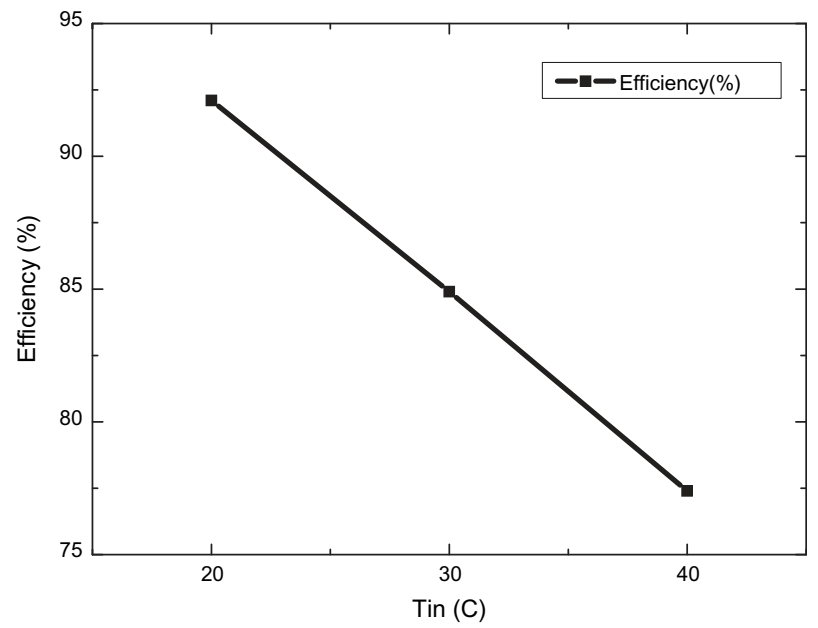

Fig. 14. Influence of inlet coolant temperature $T_{\text {in }}$ on the polymer FPSC.

incoming solar radiation which is transmitted throughout the glazing and arrives on the absorber. In these simulations $I$ varies from 350 to $1200 \mathrm{~W} \mathrm{~m}^{-2}$.

According to Table 11, increasing $I$ induces a higher $\Delta T$. Indeed, the absorber receives more energy, thus it heats more and transfers more energy to the coolant, but the amount of heat losses on the glazing increases too, although the ratio is the same for all cases $\left(3.2 \%\right.$ of $\left.Q_{u}\right)$. Fig. 12 shows that the efficiency is not really sensitive on $I$ (see Figs. 13 and 14).

On the other hand, the effect of the incoming solar radiation is more sensitive on $\Delta T$ (difference between temperature inlet $T_{\text {in }}$ and temperature outlet $\left.T_{\text {out }}\right)$. Therefore the incoming solar radiation has an important effect on coolant heating, but a small effect on the polymer FPSC's efficiency. According to Fig. 12, $\Delta T$ is proportional to $I$. In fact for this configuration (mass flow rate, inlet coolant temperature, collector inclination, etc.) the increase in irradiation is beneficial to the polymer FPSC's performance.

\subsection{Influence of inlet coolant temperature}

This section presents the results obtained in the parametric study of the influence the inlet coolant temperature has on the polymer FPSC's performance. Three $P$-values of

Table 12

Results of the parametric study of inlet coolant temperature.

\begin{tabular}{llll}
\hline$T_{\text {in }}(\mathrm{C})$ & 20 & 30 & 40 \\
\hline$T_{\text {out }}(\mathrm{C})$ & 36 & 44.7 & 53.4 \\
$\Delta T(\mathrm{C})$ & 16 & 14.7 & 13.4 \\
$T_{\text {glass-inner }}(\mathrm{C})$ & 22.3 & 24.4 & 26.5 \\
$T_{\text {abs-upper }}(\mathrm{C})$ & 31.2 & 40.5 & 49.7 \\
$Q_{u}(\mathrm{~W})$ & 33.3 & 30.7 & 28 \\
$\left.\phi_{u}(\mathrm{~W} \mathrm{~m})^{-2}\right)$ & 736.7 & 679.4 & 618.9 \\
$Q_{l}(\mathrm{~W})$ & 1.1 & 2 & 2.9 \\
$\left.\phi_{l}(\mathrm{~W} \mathrm{~m})^{-2}\right)$ & 11.8 & 21.5 & 31.5 \\
$\eta(\%)$ & 92.1 & 84.9 & 77.4 \\
\hline
\end{tabular}




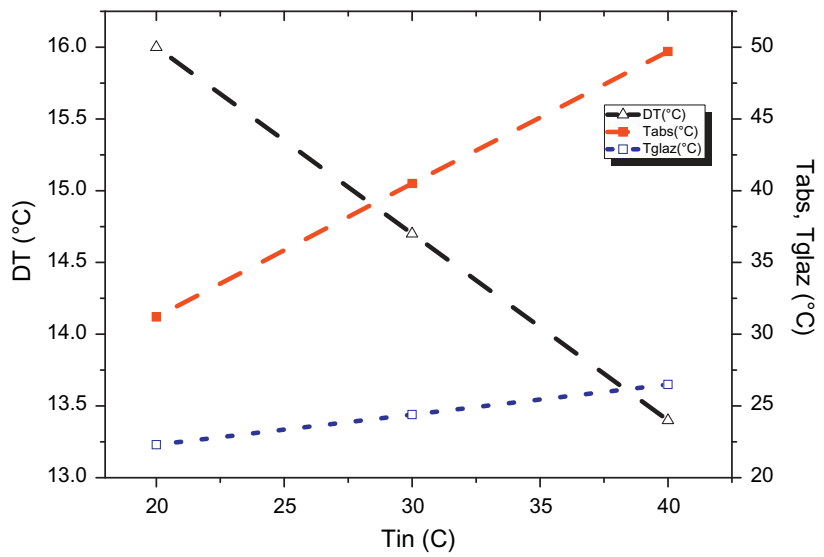

Fig. 15. Temperature evolution $\left(\Delta T, T_{a b s}\right.$ and $\left.T_{\text {glaz }}\right)$ in the study of inlet coolant temperature influence $T_{\text {in }}$.

the inlet coolant temperature $T_{\text {in }}$ have been considered in Table 12.

The results show that $\Delta T$ decreases as $T_{\text {in }}$ increases. In fact the heat exchange between the absorber and the coolant depends on the temperature difference between the absorber and the coolant. The efficiency increases quasi-linearly to $\Delta T$ for the considered control parameter.

$\phi_{a b s-c o o l}=h_{\text {conv }} \cdot \Delta T_{a b s-c o o l}$

where $\phi_{a b s-c o o l}$ is the total heat flux transferred, $h_{\text {conv }}$ the heat transfer coefficient and $\Delta T_{a b s-c o o l}$ the temperature difference between the absorber and the coolant. Fig. 15 shows that the absorber's temperature rises faster than the glazing's temperature. This temperature elevation causes more thermal losses in the polymer FPSC, consequently its efficiency decreases in these conditions. According to Eq. (17) the higher $\Delta T_{a b s-c o o l}$ is the higher the heat flux transferred to the coolant. As $T_{i n}$ rises $\Delta T_{a b s-c o o l}$ decreases, consequently heat transfer is lowered. This explains the decrease in FPSC efficiency. To promote a better heat exchange between the absorber and the coolant, the inlet coolant temperature must at least equal the ambient temperature.

\section{Conclusion}

In this paper, numerical investigations on the thermal behavior of a polymer FPSC have been performed. The goal was to evaluate the influence of various operating and design parameters on the polymer FPSC's performance. The results show that increasing the polymer FPSC's length has no effect on the solar collector's performance, whereas the air gap thickness does, an optimal performance being obtained at an air gap thickness of around to $10 \mathrm{~mm}$ in our case. Increasing the mass flow rate also improves the polymer FPSC's efficiency, but the coolant's outlet temperature is then reduced. Finally, the incoming solar radiation has a small influence on such a collector's efficiency, but drives roughly linearly the outlet-inlet temperature difference. Concerning the inlet coolant's temperature it has been shown that it has an important influence on the polymer collector performance. To have a good performance, the inlet coolant's temperature must be at least the ambient temperature.

This work highlights the trends to follow in order to optimize a polymer FPSC. Indeed the classical trends concerning $T_{i n}, \dot{m}$ and $I$ have been investigated in the present simulations. On the other hand the air gap $e$ influence has been computed by taking into account, in a coupled way, the three heat transfer modes in the present 3D computation.

This numerical study is a first step towards understanding the thermal behavior of polymer FPSCs, on the way to a better optimization in order to design in the future more economically competitive thermal solar collectors.

\section{Acknowledgment}

The authors gratefully acknowledge Oseo for their financial support in the SolaireDuo Project.

\section{References}

Akthar, N., Mullick, S., 2012. Effect of absorption of solar radiation in glass-cover(s) on heat coefficents in upward heat flow in single and double glazed flat-plate collectors. International Journal of Heat and Mass Transfer 55, 125-132.

Alvarez, A., Cabeza, O., Mutiz, M., Varela, L., 2010. Experimental and numerical investigation of a flat plate solar collector. Energy 55, 37073716.

Amraqui, S., 2009. Modélisation des transferts thermiques couplées dans un capteur solaire thermique avec cellules ani-pertes. Ph.D. Thesis, Université de provence.

Arnold, J., Catton, I., Edwards, D., 1976. Experimental investigation of natural convection in inclined rectangular regions of differing aspect ration. Heat Transfer 98, 67-71.

Arnold, J., Edwards, D., Catton, I., 1977. Effect of tilt and horizontal aspect ratio on natural convection in a rectangular honeycomb. ASME, transactions, series C. Journal of Heat Transfer 99, 120-122.

Benkhelifa, A., 1998. Optimisation d'un capteur solaire plan. Revue des Energies Renouvelables SIPE, 13-18.

Cardonnel, C. 1983. Solaire actif et passif (Conception, bilan thermique, habitat), les éditions parisiennes.

Cd-Adapco, User Guide, StarCCM+ version 4, Cd-Adapco, 2009.

Charalambous, P., Maidment, G., Kalogirou, S., Yiakoumetti, K., 2007. Photovoltaic thermal $(\mathrm{p} / \mathrm{t})$ collectors: a review. Applied Thermal Engineering 27, 275-286.

Cristofari, C., Notton, G., Poggi, P., Louche, A., 2002. Modeling and performance of a copolymer solar water heating collector. Solar Energy 72, 99-112.

Dagdougui, H., Ouammi, A., Robba, M., Solice, R., 2011. Thermal analysis and performance optimization of a solar water heater flat plate collector: application to Tetouan (marocco). Renewable Energy $15,630-638$.

Fan, J., Shah, L., Furbo, S., 2007. Flow distribution in a solar collector panel with horizontally inclined absorber strips. Solar Energy 81, 1501-1511.

Ferahta, F., Bougoul, S., Ababsa, D., Abid, C., 2011. Flow distribution in a solar collector panel with horizontally inclined absorber strips. Energy Procedia 6, 176-184. 
Filloux, A., 2001. Eau Chaude Solaire (Manuel pour la conception, le dimensionnement et la réalisation des installations collectives). ADEME, TECSOL.

Hellstrom, P.N.B., Adsten, M., 2003. The impact of optical and thermal properties on the performance of flat plate solar collectors. Renewable Energy 28, 331-344.

Hollands, K., 1965. Honeycomb devices in flat plate solar collectors. Solar Energy 9, 159-164.

Hollands, K., 1973. Natural convection in horizontal thin-walled honeycomb panels. Heat Transfer 95, 439-444.

Hossain, M., Saidur, R., Fayaz, H., Rahim, N., Islam, M., Ahamed, J., Raham, M., 2011. Review on solar water heater collector and thermal energy performance of circulating pipe. Renewable and Sustainable Energy Reviews 15, 3801-3812.

Ibrahim, A., Yusof, M., Othman, Ruslan, M.H., Mat, S., Sopian, K., 2011. Recent advances in flat plate photovoltaic/thermal (pv/t) solar collectors. Renewable and Sustainable Energy Reviews 15, 352-365.

Jaisankar, S., Ananth, J., Thulasi, S., Jayasuthakar, S.T., Sheeba, K., 2011. A comprehensive review on solar water heaters. Renewable and Sustainable Energy Reviews 15, 3045-3050.

Kalogirou, S.A., 2004. Solar thermal collectors and applications. Progress in Energy and Combustion Science 30, 231-295.

Kumar, S., Mullick, S., Glass cover temperature and top heat loss coefficient of a single glazed flat plate solar collector with nearly vertical configuration. Ain Shams Engineering Journal.

Kumar, R., Rosen, M.A., 2010. Thermal performance of integrated collector storage solar water heater with corrugated absorber surface. Applied Thermal Engineering 30, 1764-1768.

Kundu, B., 2010. Analytic method for thermal performance and optimization of an absorber plate fin having variable thermal conductivity and overall loss coefficient. Applied Energy 87, 2243-2255.

Kuo, C.-F.J., Su, T.-L., Jhang, P.-R., Huang, C.-Y., Chiu, C.-H., 2011. Using the taguchi method and grey relational analysis to optimize the flat-plate collector process with multiple quality characteristics in solar energy collector manufacturing. Energy 26, 3554-3562.

Martinopoulos, G., Missirlis, D., Tsilingiridis, G., Yakinthos, K., Kyriakis, N., 2010. CFD modeling of a polymer solar collector. Renewable Energy 35, 1499-1508.

Mekhilef, S., Saidur, R., Safari, A., 2011. A review on solar energy use in industries. Renewable and Sustainable Energy Reviews 15, 1777-1790.

Slaman, M., Griessen, R., 2009. Solar collector overheating protection. Solar Energy 83, 982-987.

Sookdeo, S., Siddiqui, K., 2010. Investigation of the flow field inside flatplate collector tube using piv technique. Solar Energy 84, 917-927.

Varol, Y., Oztop, H., 2008. A comparative numerical study on natural convection in inclined wavy and flat-plate solar collectors. Building and Environment 43, 1535-1544.

Vestlund, J., Dalenback, J.-O., Ronnelid, M., 2012. Flow distribution in a solar collector panel with horizontally inclined absorber strips. Solar Energy 86, 13-25.

Zambolin, E., Del, D., 2010. Experimental analysis of thermal performance a flat plate and evacuated tube solar collectors instationary strandard and daily conditions. Solar Energy 84, 1382-1396. 